\title{
Pentacyclic Triterpenes of the Lupane, Oleanane and Ursane Group as Tools in Cancer Therapy
}

Author

Affiliations
Melanie N. Laszczyk ${ }^{1,2}$

${ }^{1}$ Betulin Institut, Darmstadt, Germany

${ }^{2}$ Carl Gustav Carus-Institut, Niefern-Öschelbronn, Germany
Key words

- pentacyclic triterpenes

- multifunctional agent

- cancer treatment received March 28, 2009

revised July 27, 2009

accepted August 5, 2009

Bibliography

DOI 10.1055/s-0029-1186102 Published online September 9, 2009

Planta Med 2009; 75 :

1549-1560 @ Georg Thieme Verlag KG Stuttgart · New York . ISSN 0032-0943

Correspondence

Dr. Melanie N. Laszczyk

Betulin-Institut

Blumenstr. 25

64297 Darmstadt

Germany

Phone: +497233829371

m.laszczyk@betulin-institut.de

\section{Abstract}

$\nabla$

Today cancer treatment is not only a question of eliminating cancer cells by induction of cell death. New therapeutic strategies also include targeting the tumour microenvironment, avoiding angiogenesis, modulating the immune response or the chronic inflammation that is often associated with cancer. Furthermore, the induction of redifferentiation of dedifferentiated cancer cells is an interesting aspect in developing new therapy strategies. Plants provide a broad spectrum of potential drug substances for cancer therapy with multifaceted effects and targets. Pentacyclic triterpenes are one group of promising secondary plant metabolites. This review summarizes the potential of triterpenes belonging to the lupane, oleanane or ursane group, to treat cancer by different modes of action. Since Pisha et al. reported in 1995 that betulinic acid is a highly promising anticancer drug after inducing apoptosis in melanoma cell lines in vitro and in vivo, experimental work focused on the apoptosis inducing mechanisms of betulinic acid and other triterpenes. The antitumour effects were subsequently confirmed in a series of cancer cell lines from other origins, for example breast, colon, lung and neuroblastoma. In addition, in the last decade many studies have shown further effects that justify the expectation that triterpenes are useful to treat cancer by several modes of action. Thus, triterpene acids are known mainly for their antiangiogenic effects as well as their differentiation inducing effects. In particular, lupane-type triterpenes, such as betulin, betulinic acid and lupeol, display anti-inflammatory activities which often accompany immune modulation. Triterpene acids as well as triterpene monoalcohols and diols also show an antioxidative potential. The pharmacological potential of triterpenes of the lupane, oleanane or ursane type for cancer treatment seems high; although up to now no clinical trial has been pub- lished using these triterpenes in cancer therapy. They provide a multitarget potential for coping with new cancer strategies. Whether this is an effective approach for cancer treatment has to be proven. Because various triterpenes are an increasingly promising group of plant metabolites, the utilisation of different plants as their sources is of interest. Parts of plants, for example birch bark, rosemary leaves, apple peel and mistletoe shoots are rich in triterpenes and provide different triterpene compositions.

\section{Abbreviations \\ $\nabla$}

ACC: antigen-dependent complementmediated cytotoxicity

ADCC: antibody-dependent cell mediated cytotoxicity

APN: aminopeptidase $\mathrm{N}$

ARE: antioxidant response element

BAEC: bovine aortic endothelial cell

CAM: chick embryo chorioallantoic membrane

CAT: catalase

COX-2: cyclooxygenase-2

DMBA: 7,12-dimethylbenz(a)anthracene

DMSO: dimethylsulfoxide

ECM: extracellular matrix

FGF: fibroblast growth factor

GM-CSF: granulocyte-macrophage colonystimulating factor

GSH: glutathione

HUVEC: human umbilical vein endothelial cell

ID: inhibition dose

IL: interleukin

iNOS: inducible NO-synthase

LD: lethal dose

$\mathrm{NADP}^{+}$: nicotinamide adenine dinucleotide phosphate

NF- $k$ B: $\quad$ nuclear factor-kappaB

NO: nitric oxide 
Nrf2: $\quad$ nuclear factor E2-related factor 2

PCNA: proliferating cell nuclear antigen

$\mathrm{PGE}_{2}$ : $\quad$ prostaglandin $\mathrm{E}_{2}$

$\mathrm{PLA}_{2}$ : $\quad$ phospholipase $\mathrm{A}_{2}$

PPAR: $\quad$ peroxisome proliferator activated receptor

ROS: $\quad$ reactive oxygen species

SOD: $\quad$ superoxide dismutase

$\begin{array}{ll}\text { Sp: } & \text { specificity protein } \\ \text { TE: } & \text { triterpene dry extract } \\ \text { TNF: } & \text { tumour necrosis factor } \\ \text { TPA: } & \text { 12-O-tetradecanoylphorbol-13-acetate } \\ \text { TRPC6: } & \text { transient receptor potential channel } 6 \\ \text { VEGF: } & \text { vascular endothelial growth factor }\end{array}$

Sp: $\quad$ specificity protein

TNF: $\quad$ tumour necrosis factor

TPA: 12-0-tetradecanoylphorbol-13-acetate

VEGF: vascular endothelial growth factor

\section{Introduction}

$\nabla$

Today solid tumours are no longer considered as a mere accumulation of abnormal, malignant cancer cells. The tumour environment, the tumour stroma, is becoming more and more important. Therefore, treatment strategies have to be changed. Most therapies now try to eliminate cancer cells by inducing apoptosis or necrosis. New therapy strategies include the treatment of the tumour environment, avoiding angiogenesis and modulating the immune response or the chronic inflammation that is often associated with cancer promotion and progression. Another approach is to redifferentiate proliferating tumour cells.

In addition, chemoprevention is important to avoid cancer promotion. Cancer results from a multistage carcinogenesis process: initiation, promotion and progression. Because reducing the initiation phase to a zero level is impossible, the most efficient intervention would be at the promotion phase to eliminate premalignant cells before they become malignant [1]. Therefore, the concept of delaying or preventing this transformation is worth testing in future studies [2].

Pentacyclic triterpenes are secondary plant metabolites which arise from cyclization of squalene [3]. This article focused on triterpenes of the lupeol, oleanane and ursane type. They are found in different plant organs, e.g., in bark, cork, or in the wax covering leaves or peel. Low amounts $(<0.1 \%$ of the dry weight of a plant organ) are ubiquitously present in plants. However, there are a few species that display a high amount of these pentacyclic triterpenes ( $>1 \%$ of the dry weight of the plant organ). The highest triterpene amount has been found in the outer bark of white birch. The white outer bark contains up to $34 \%$ (w/w) betulin [4]. Beside the outer bark of birch, leaves of rosemary and olive, mistletoe as well as plane tree bark and apple peelings contain more than $1 \%$ $(\mathrm{w} / \mathrm{w})$ of these pentacyclic triterpenes ( Table 1$)$. These plants can be used to obtain triterpene dry extracts consisting of 50$90 \%(w / w)$ triterpenes [5]. Depending on the plant material, lupeol, betulin, betulinic acid, oleanolic acid, ursolic acid or an equal mixture of these substances are the main components of such dry extracts [6] (๑ Fig. 1). This kind of triterpene extract may be used as starting material for further pharmaceutical development.

In the last 15 years hundreds of publications have highlighted the broad spectrum of biological activities of lupane, oleanane and ursane triterpenes. The literature search for this review is based on an actual PubMed search focused on the last two years. On account of the low water solubility of triterpenes, special attention was given to the concentrations used in in vitro experiments. Concentrations above $100 \mu \mathrm{M}$ often bias the results, because of an insoluble fraction. In case of in vivo data, we included effects that are described by almost all different work groups.

Because of their cytotoxicity against various cancer cell lines the group of lupane, oleanane and ursane triterpenes are considered as promising anticancer drugs. Nevertheless, due to their various pharmacological activities including antiangiogenic, anti-inflammatory as well as antioxidant effects and the ability to enhance cell differentiation, they are more than a simple cytotoxic anticancer drug and are suitable for modern cancer strategies ( Fig. 2). Moreover, they are regarded as essential parts of human nutrition because of their chemopreventive potential to fend off cancer promotion $[7,8]$.

\begin{tabular}{|c|c|c|c|c|}
\hline Plant & Part & Triterpene & Amount & Reference \\
\hline \multirow[t]{4}{*}{ Betula alba L., Betulaceae } & bark & lupeol & $1-2 \%$ & [5] \\
\hline & & betulin & $10-34 \%$ & {$[4,5]$} \\
\hline & & betulinic acid & $0.5-1.5 \%$ & {$[5]$} \\
\hline & & oleanolic acid & $0-1.5 \%$ & [5] \\
\hline \multirow[t]{3}{*}{ Rosmarinus officinalis L., Lamiaceae } & leaves & betulinic acid & $1.5 \%$ & {$[6]$} \\
\hline & & oleanolic acid & $1.2 \%$ & {$[6]$} \\
\hline & & ursolic acid & $3.0 \%$ & {$[6]$} \\
\hline Malus domestica Mill., Rosaceae & $\begin{array}{l}\text { fruit } \\
\text { peel }\end{array}$ & ursolic acid & $2.0 \%$ & {$[6]$} \\
\hline Platanus L., Platanaceae & bark & betulinic acid & $2.4 \%$ & {$[6]$} \\
\hline Viscum album L., Viscaceae & sapling & oleanolic acid & $1.0 \%$ & {$[6]$} \\
\hline Olea europaea L., Oleaceae & leaves & oleanolic acid & $3.1 \%$ & {$[6]$} \\
\hline Nerium oleander L., Apocynaceae & leaves & ursolic acid & $1.2 \%$ & {$[6]$} \\
\hline Arctostaphylos uva-ursi L., Ericaceae & leaves & ursolic acid & $1.2 \%$ & {$[6]$} \\
\hline Coffea L., Rubiaceae & leaves & ursolic acid & $1.8 \%$ & {$[6]$} \\
\hline Eucalyptus L’Hér., Myrtaceae & leaves & ursolic acid & $1.2 \%$ & {$[6]$} \\
\hline Lavandula angustifolia L., Lamiaceae & leaves & ursolic acid & $1.6 \%$ & {$[6]$} \\
\hline Salvia officinalis L., Lamiaceae & leaves & ursolic acid & $1.8 \%$ & {$[6]$} \\
\hline Syzygium aromaticum L., Myrtaceae & flowers & oleanolic acid & $1.6 \%$ & {$[6]$} \\
\hline Thymus vulgaris L., Lamiaceae & leaves & ursolic acid & $1.0 \%$ & {$[6]$} \\
\hline
\end{tabular}

Table 1 Plants which display a high amount of pentacyclic triterpenes. 


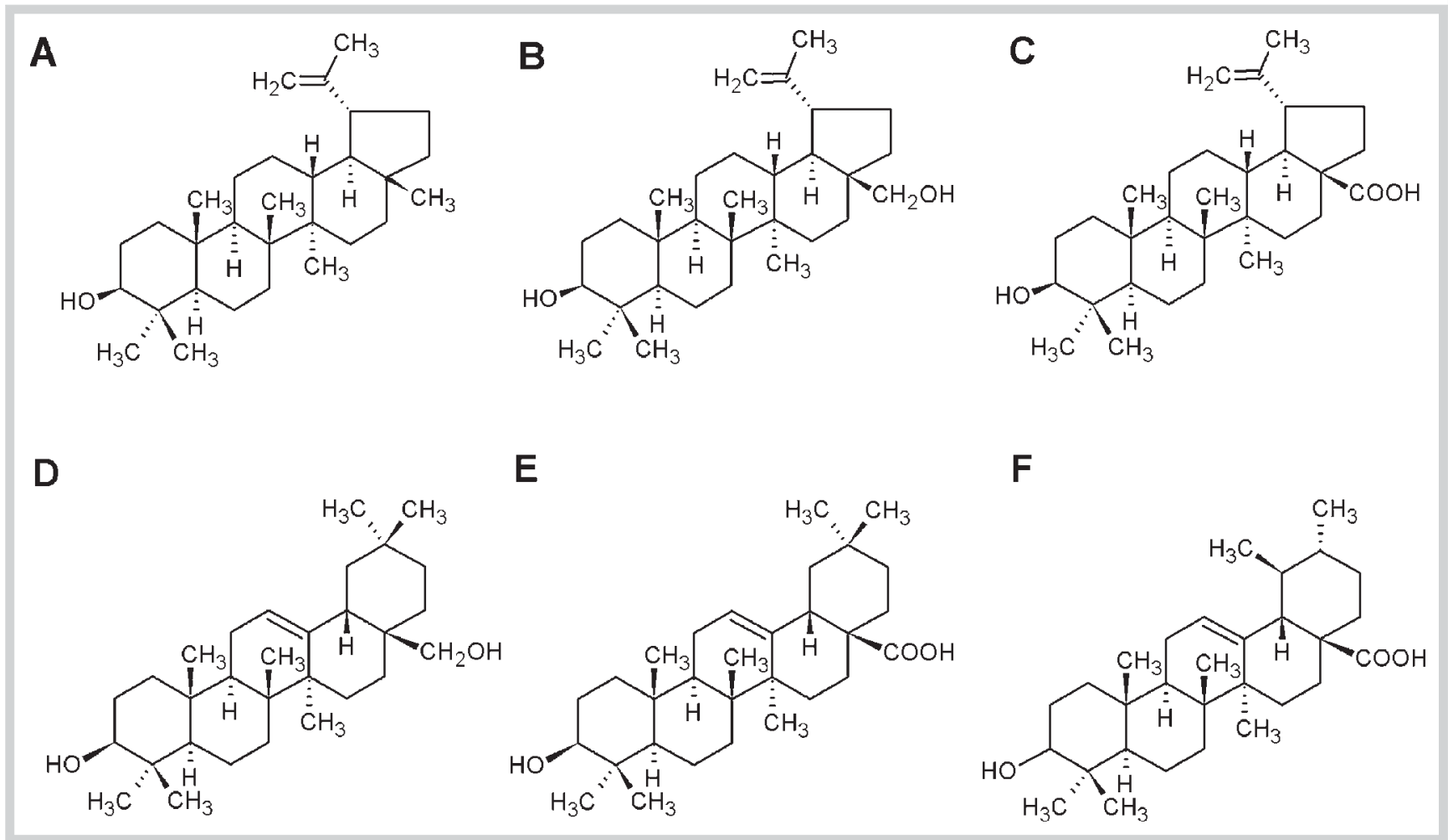

Fig. 1 Chemical structures of (A) lupeol, (B) betulin, (C) betulinic acid, (D) erythrodiol, (E) oleanolic acid and (F) ursolic acid. Lupeol, betulin and betulinic acid belong to the lupan type pentacyclic triterpenes consisting of four six-rings and one five-ring, whereas erythrodiol and oleanolic acid exhibit an oleanan structure with five six-rings. This is quite similar to the ursan group, which is represented by ursolic acid. The difference between the oleanan and the ursan type is the methyl-group localization of the E-ring.

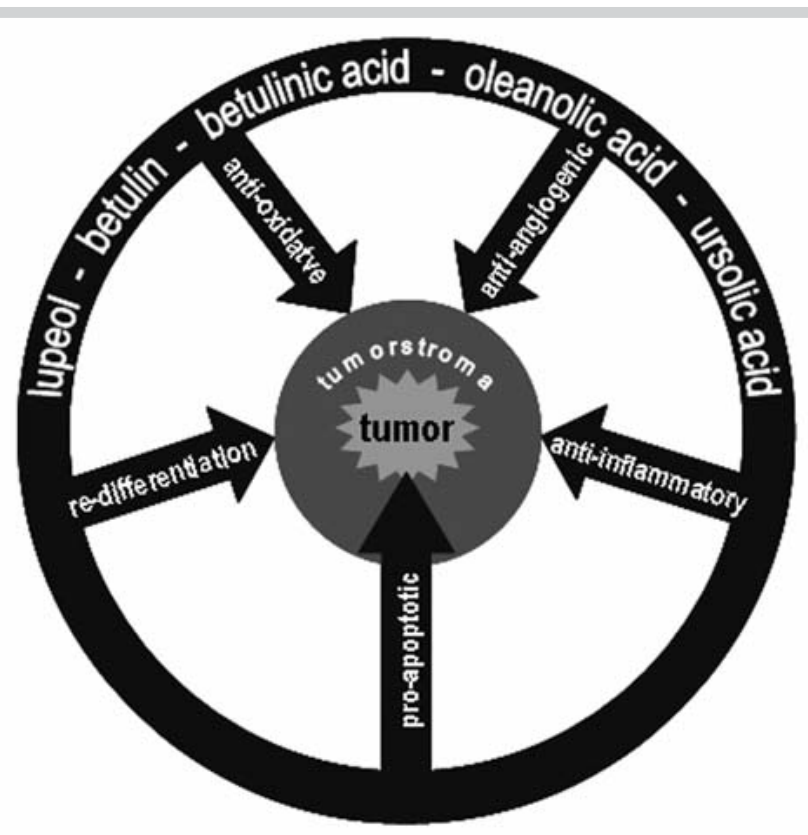

Fig. 2 Pentacyclic triterpenes such as lupeol, betulin, betulinic acid, erythrodiol, oleanolic acid and ursolic acid exhibit various pharmacological activities. Besides targeting tumour cells by induction of apoptosis, they also modulate the tumour environment displaying antiangiogenic, anti-inflammatory as well as antioxidant effects and enhancing cell differentiation. The efficacy of each single compound might differ with respect to the various activities, so the combination of these substances might have a benefit in order to treat cancer from different from different angles in modern cancer strategies.

\section{Apoptosis}

$\nabla$

Induction of apoptosis by pro-apoptotic agents is one important part of cancer therapy. But apoptosis in cancer cells is often impaired or even blocked by mutated genes regulating the cell cycle or an imbalanced ratio of pro- and antiapoptotic proteins. Therefore it is necessary to target different steps of the apoptotic process to bypass such blocks with respect to the type of cancer. This review highlights only a few aspects of the knowledge about triterpenes and apoptosis. But it should give an impression of the diversity of mechanisms triggered by these triterpenes and with it the chance to overcome apoptosis resistance in cancer cells.

Triterpenes trigger apoptosis by different modes of action, as extensively described in a series of reviews, especially for betulinic acid [7-9]. First it was assumed that betulinic acid is a selective cytotoxic compound against melanoma cells. However, up to now a large panel of cancer cell lines have proven to be sensitive to betulinic acid and other pentacyclic triterpenes. It is also assumed by some authors that there is a selective sensitivity against malignant cells. Nevertheless, cytotoxicity against primary cells such as fibroblasts, melanocytes, keratinocytes, neuronal cells and peripheral blood lymphocytes is reported, but they seem to tolerate higher triterpene concentrations than cancer cells of the same origin [10-14]. Whether this may result in a positive effect in vivo, when cancer cells are in a united cell structure is questionable. But in the case of triterpene acids another possibility to enhance their activity in cancer tissue was observed. In vitro the activity of betulinic acid was increased by decreasing the $\mathrm{pH}$ [15]. And interestingly in athymic mice carrying human melanoma xenografts, its highest concentration after in- 
traperitoneal injection $(500 \mathrm{mg} / \mathrm{kg}$ ) compared with other tissues like liver, lung, and kidney was found in the tumour tissue, which often exhibits a lower $\mathrm{pH}$, caused by a changed metabolism. This could be an explanation of the triterpene acid accumulation in the melanoma tissue. Up to now, only a few investigations include $\mathrm{pH}$ variations $[15,16]$, but this fact could be an important factor for increasing the activity of triterpene acids in cancer treatment and should be investigated in more detail.

The apoptosis mechanism of betulinic acid has been investigated quite well and was reviewed in 2009 by Fulda [9]. In short, betulinic acid induces apoptosis via the intrinsic pathway by affecting the mitochondrial membrane potential [17] and initiates reactive oxygen species (ROS) generation linked to an activation of proapoptotic p38 MAPK and SAP/JNK kinases [18,19]. A similar increase of ROS was also observed for oleanolic acid $(25 \mu \mathrm{M})$ in astrocytoma cell lines [20]. While recently published data reported Bax/Bak-independent apoptosis induction by betulinic acid in various cancer cell lines [21], a number of publications show a modulation of anti- and pro-apoptotic proteins of the Bcl-2 family $[13,22-25]$. The modulation of pro- and antiapoptotic factors is complex and probably cell-type-dependent. It is likely that context dependency also plays a role with respect to nuclear factor kappa-B (NF- $k \mathrm{~B}$ ) modulation. While NF- $k$ B is activated by betulinic acid $(20 \mu \mathrm{M})$ in a variety of cancer cell lines resulting in induction of apoptosis [26], NF- $k$ B inhibition is observed in chemoresistant androgen-refractory prostate cancer cells exhibiting constitutive Rel/NF- $k$ B activation [27]. Similar effects of triterpenes on NF- $k$ B related to inflammation have been observed and are discussed later. One important detail to overcome some types of apoptosis resistance is the independence of betulinic acid induced apoptosis of p53 that is frequently mutated in cancer cells $[13,22,24]$.

While apoptosis induced by betulinic acid seems to be independent of the Fas receptor [22], lupeol targets this receptor and consequently activates the extrinsic pathway via caspase 8 . For example, lupeol $(20 \mu \mathrm{M})$ significantly increased the expression of the FADD protein and the Fas receptor in androgen sensitive prostate cancer cells [28]. Furthermore, lupeol sensitises chemoresistant human pancreatic cancer cells (PaC), to undergo apoptosis by recombinant TRAIL via suppression of cFLIP [29]. Besides, various targets of lupeol are reported to overcome apoptosis resistance by inhibition of oncogenes and activation of tumour suppressor genes. At a concentration of $30 \mu \mathrm{M}$, lupeol reduces the expression of commonly overexpressed Ras oncoprotein resulting in the inhibition of the PI3K/Akt pathway that is known for promoting cell growth [30]. Coincidentally, the expression of phospho-p38 MAPK, which triggers an antiapoptotic response to tumour cells, was decreased together with NF- $k$ B occurrence. These modulations were accompanied by induction of apoptosis in the otherwise resistant pancreatic cells [30].

Also ursolic acid and oleanolic acid exhibit pro-apoptotic activity, as reviewed by Ovesna and colleagues in 2004 [8]. Recent results indicated a modulation of the $\mathrm{Bcl}-2$ protein family due to a suppression of NF- $k$ B by ursolic acid $(50 \mu \mathrm{M})$ in B16.F10 mouse melanoma cells. Induction of apoptosis was accompanied by activation of p53 and caspase-3 gene expression [31]. Oleanolic acid $(80 \mu \mathrm{M})$ showed apoptosis induction in leukaemia cells (HL60) via activation of caspase- 9 and caspase- 3 accompanied by the cleavage of poly(ADP-ribose) polymerase (PARP) [32].

Betulin has often been found to be inactive or weakly active against several cancer cell lines such as melanoma (MEL-2), epidermoid carcinoma (KB) [33], leukaemia (HL60, U937, K562) or neuroblastoma (GOTO, NB-1) [34]. However, in nonmalignant, immortalised $\mathrm{HaCaT}$ keratinocytes induction of caspase-dependent apoptosis has been observed [5] and recently, Pyo et al. revealed anticancer activity of betulin $(20 \mu \mathrm{M})$ against a human lung cancer cell line (A549) by induction of apoptosis [35]. Erythrodiol, the closely related diol of the oleanane group, has not been investigated very thoroughly either, but in 2008 apoptotic activity in HT-29 human adenocarcinoma cells at concentrations of 50$150 \mu \mathrm{M}$ was reported [36]. In the case of betulin and erythrodiol, it is difficult to evaluate their pro-apoptotic potential compared to betulinic acid, because of the low amount of published data.

Sometimes only moderate pro-apoptotic effects of triterpenes are observed in vitro, as reported for immortalised HaCaT keratinocytes or human epidermoid carcinoma cells (A431) treated with a triterpene dry extract from birch bark containing $80 \%$ betulin and up to $4 \%$ betulinic acid and smaller amounts of lupeol and oleanolic acid [5]. It was only able to induce a twofold higher apoptosis rate in $\mathrm{HaCaT}$ keratinocytes. At first these results seem to have no relevance for therapeutic treatment. Nevertheless the triterpene extract was successful in vivo treating actinic keratosis [37].

In summary, the apoptotic pathway for betulinic acid is well known. Triggering the intrinsic pathway via destruction of the mitochondrial membrane potential and including MAP kinase and PI3K/Akt pathways, seems to be the mode of action. In respect of the antioxidative activity discussed later, the induction of ROS species in the case of apoptosis is highly interesting. Potentially the concentration is the critical parameter causing apoptosis or an antioxidative effect. Oleanolic acid may act in a way similar to betulinic acid by activating caspase- 9 .

Unlike triterpene acids, lupeol triggers the extrinsic pathway via the Fas-receptor. There is still a lack of data for the diols betulin and erythrodiol, thus a prediction of their mechanism is not yet possible.

Due to the different mechanisms triggered, the use of different triterpenes, also in a mixture may increase the chance of overcoming the chemoresistence of tumour cells. At the moment, this is the conclusion drawn only from the results of various researches carried out independently. Only well organised widespread analysis of a cancer cell panel treated with different triterpenes under standardised parameters could generate really comparable data for determining which triterpene or triterpene mixtures exhibit the best chance of being active against a particular cancer cell. But this could be an opportunity for tapping the full potential of triterpenes that induce apoptosis.

\section{Antiangiogenic Effects}

$\nabla$

Angiogenesis is a key process for the outgrowth of cancer cells and their spread into other tissues. Therefore, suppressing this process is one important pillar of cancer treatment. There are four key steps in angiogenesis which are potential therapeutic targets: degradation of extracellular matrix, migration and proliferation of aortic endothelial cells and the formation of new blood vessels. The initial results in 1995 of Sohn and colleagues provided an indication that ursolic acid and oleanolic acid have antiangiogenic effects on bovine aortic endothelial cells (BAEC) in the CAM (chick embryo chorioallantoic membrane) assay [38]. Here, ursolic acid $\left(\mathrm{ID}_{50}: 4 \mu \mathrm{M}\right)$ was more effective than oleanolic acid $\left(\mathrm{ID}_{50}: 40 \mu \mathrm{M}\right)$. However, the key steps of angiogenesis targeted by triterpene acids had not been identified at this time. Further investigations focussing on the different key steps disclosed ef- 
fects on the angiogenic process but these proved controversial. In serum free cultures of human umbilical vein endothelial cells (HUVECs), ursolic acid (10-100 $\mu \mathrm{M})$ increases expression of adhesion molecules that support angiogenesis, such as ICAM-1 and CD31, and the expression of angiogenic growth factors, particularly vascular endothelial growth factor (VEGF) and fibroblast growth factor-2 (FGF-2) [39]. This suggests a possible support of the migration step and the structure formation process. Furthermore, 4-20 $\mu \mathrm{M}$ ursolic acid failed to produce a significant inhibition of the invasion capability of BAEC through matrigel. In addition, the degradation of extracellular matrix (ECM) by ECM degradation proteins as MMP-2 and urokinase was assumed to be stimulated by ursolic acid $(4 \mu \mathrm{M})$ due to an increased expression shown by gelatinase and urokinase zymography of these enzymes in BAEC [40]. But this should be investigated in more detail, considering that two years later Jedinak found a strong inhibition of urokinase activity by ursolic acid in a cell free system [41]. Despite the enhancement of pro-angiogenic factors, in 2004 Cardenas confirmed Sohn's (1995) observation of the antiangiogenic effect of ursolic acid in the CAM assay. Furthermore, ursolic acid treatment of HUVECs and rat aortic rings that were stimulated by cultivation in medium supplemented with serum in contrast to serum free medium surprisingly caused inhibition of the angiogenic phenotype, including the formation of a capillary network-like structure by HUVECs and a greater extent of endothelial sprouting in rat aortic rings [39]. Due to the sometimes contradictory effects of ursolic acid on different steps of angiogenesis, one must be cautious concerning its antiangiogenic potential. The generation of in vivo data is necessary in order to include the influence of the tissue milieu and thus appropriately evaluate its effects.

For betulinic acid, older studies revealed that it inhibits enzymatic activity of aminopeptidase $\mathrm{N}$ (APN) in a cell free system [42]. APN is a widely distributed, membrane-bound, zinc-dependent metalloproteinase that is known to play an important role in tumour-vasculogenesis and is essential for the endothelial cell tube formation $[43,44]$. Betulinic acid $(2 \mu \mathrm{M})$ potently inhibits basic fibroblast growth factor (bFGF)-induced invasion and tube formation of BAECs [45]. Initially it was assumed that APN could be the target of betulinic acid. Kwon et al. confirmed that betulinic acid strongly inhibits enzymatic activity of APN in a cell free system, but not when enzymatic activity was measured in betulinic acid treated endothelial cells. He provided evidence that the antiangiogenic activity of betulinic acid was accompanied by modulation of the mitochondrial membrane function by decreasing the mitochondrial redox potential. This effect could be blocked by different mitochondrial permeability transition inhibitors such as cyclosporine A or bongkrekic acid. In view of the effects of betulinic acid on the mitochondrial membrane, this seems to be a target structure worth considering. But in this context, the modulation of the mitochondrial membrane does not cause the release of apoptogenic factors that directly trigger cell death. Betulinic acid at up to $9 \mu \mathrm{M}$ did not affect the endothelial cell viability in the formed tubes. Kwon hypothesised that betulinic acid had a specific effect on the angiogenic differentiation of endothelial cells, rather than an antiproliferative activity [45]. It is known, that a modulation of the mitochondrial oxidative phosphorylation can enhance angiogenic differentiation of endothelial cells, stopping their proliferative activity [46]. However, in a human prostate cancer cell line (LNCaP) and in vivo, betulinic acid acts via decreasing expression of VEGF [47]. Thus there might be also an antiproliferative effect. The mechanism might be due to activation of selective proteasome-dependent degradation of the transcription factors specificity protein 1 (Sp1), Sp3, and Sp4 which regulate the VEGF expression and that are mostly overexpressed in tumours, as was shown by Chintharlapalli and colleagues [47]. The concentration-dependent effect on the transcription factors and the expression of VEGF by betulinic acid could be fully blocked by using a proteasome inhibitor.

Only one publication reports an antiangiogenic effect of lupeol. You and colleagues found that lupeol also inhibits HUVEC tube formation [48].

Based on the current literature, primarily triterpene acids seem to have an antiangiogenic effect. However, to clarify the exact mechanisms by which they exert this effect more experimental work is still needed, even if there are some doubts in the case of ursolic acid because of the upregulation of pro-angiogenic factors such as MMP-2 or VEGF in vitro. It is necessary to interpret these pro-angiogenic data very carefully. There are four key steps in angiogenesis. These include degradation of the extracellular matrix, migration and proliferation of aortic endothelial cells and the formation of new blood vessels. All four steps are necessary for successful angiogenesis. Most in vitro experiments focus only on parts of the process. This does not enable a prediction of full angiogenesis. Instead, in vivo models, such as the CAM assay, consider the whole process. Thus they provide information about the efficacy of the substances on the end result, namely forming new blood vessels, i.e., not just on one essential factor in a complex network, such as VEGF.

Nevertheless, the in vitro data give hints for understanding the mechanism. In respect of the differentiation inducing activity of triterpenes discussed later, the most interesting result is that besides the regulation of endothelial cell proliferation by modulation of growth factors such as VEGF, the aspect of inducing differentiation to stop proliferation may also play a role in the angiogenic efficacy of triterpenes.

\section{Anti-inflammatory Effects}

$\nabla$

Recent studies have revealed a clear role for inflammation in the development and progression of cancer and in the immune response against it by orchestrating the tumour supporting environment [49].

Lupanes, oleananes and ursanes applied orally or topically exhibit significant anti-inflammatory activity in vivo. This was demonstrated in 12-0-tetradecanoylphorbol-13-acetate (TPA), carrageenan, serotonin or croton oil induced paw/ear oedema tests, as well as in arthritic animal models [50-56]. Efforts to work out the underlying mechanism in vitro are in progress (reviewed in [7,8,57-59]) and several potential targets have been discovered. Besides direct effects on the morphology or the activity of immune cells, such as macrophages, dendritic cells, T cells or other leukocytes, which may suppress the immune response [60-63], an influence on pro-inflammatory cytokines, e.g., TNF- $\alpha$, INF $\gamma$, IL-1 $\beta$, IL-6, IL-2, IL-4, IL-5, IL-8, or IL-13 $[31,50,60,64-66]$ has been reported.

The expression of these cytokines is regulated by the transcription factor NF- $k$ B, which is therefore a pivotal target. Furthermore, NF- $k$ B is commonly overexpressed in cancer cells. On the one hand this may support the maintenance of a chronically inflamed microenvironment and on the other hand it often suppresses apoptosis of the tumour cells [67]. In the last few years, several groups have published controversial data concerning the 
activity of betulinic acid and ursolic acid on NF- $k B$ [26,68]. Kasperczyk et al. [26] postulated an NF- $k$ B activating effect of betulinic acid (13-22 $\mu \mathrm{M})$ on various cancer cell lines (neuroblastoma, melanoma, glioblastoma). In contrast, in 2003 Takada and Aggarwal described an inhibition of NF- $k$ B regulated cyclooxygenase-2 (COX-2) expression and determined a maximal suppressive effect of betulinic acid at a concentration of $30 \mu \mathrm{M}$ on NF- $k \mathrm{~B}$ in colon carcinoma cells [68]. Similarly NF- $k$ B in melanoma cells was inhibited by ursolic acid $(50 \mu \mathrm{M})$ accompanied by downregulation of pro-inflammatory cytokines such as TNF- $\alpha$; IL- $1 \beta$, IL- 6 , and GM-CSF and apoptosis occurred after $48 \mathrm{~h}$ [31]. Also, carcinogen-induced NF- $k B$ expression is decreased by ursolic acid [69]. However, in contrast to this, in resting macrophages ursolic acid and also oleanolic acid activate NF-kB causing increased expression of pro-inflammatory mediators such as TNF- $\alpha$ at concentrations of $5 \mu \mathrm{M}$ and $4 \mu \mathrm{M}$, respectively $[70,71]$.

At first these results seem to be contradictory, but the different observations could be based on concentration-dependent effects, as observed for oleanolic acid with respect to the TNF- $\alpha$ production of human mononuclear cells [65] or for betulinic acid concerning TNF- $\alpha$ and IL- $1 \beta$ production in non-stimulated RAW264.7 macrophages [63]. Another conceivable reason is the influence of the milieu or the cell status that may crucially modulate triterpene effects. Their investigation on TNF- $\alpha$ or nitric oxide (NO) production via inducible NO-synthase (iNOS) indicate that $[63,71,72]$. Using a stimulated cell system (e.g. activated macrophages) it was possible to observe an inhibition of pro-inflammatory mediators by triterpene treatment $[63,72]$. However, treatment of non-stimulated cells, such as resting macrophages, with triterpenes led to an increase of pro-inflammatory factors such as TNF- $\alpha$ or IL- $1 \beta[64,71]$. Certainly, these are in vitro data and up to now it is not clear whether these findings are meaningful for in vivo models or in therapeutic use. But triterpene-induced effects seem to be critically affected by environmental conditions.

Phospholipase $\mathrm{A}_{2}\left(\mathrm{PLA}_{2}\right)$ provides substrate for cyclooxygenase and 5-lipoxygenase. These pathways are major pathways of the inflammation process. Betulin and betulinic acid [73], as well as oleanolic acid [74], can inhibit PLA2. Downstream, COX-2 and its product prostaglandin $\mathrm{E}_{2}\left(\mathrm{PGE}_{2}\right)$ are also repressed by lupeol, betulin, betulinic, and ursolic acid $[61,63,68,75,76]$. Again COX-2 expression is regulated by NF- $\mathrm{kB}$, suggesting an inhibitory effect of triterpenes on this transcription factor $[68,77]$.

Unfortunately, the use of different cell systems, with a diverse metabolic background, plus the usage of different triterpenes, in various concentrations, precludes suggesting an exact mode of action for the anti-inflammatory effect of these substances. However, the abundance of data, and especially the in vivo observations, evidenced the anti-inflammatory potential of the listed pentacyclic triterpenes. A promising target for the triterpenes presented seems to be NF- $k$ B. A number of proteins modulated by triterpenes, such as TNF- $\alpha$, IL- 8 or COX-2 are under control of this transcription factor. However, the milieu, such as the cell status, has to be considered because it seems to have a strong influence on the triterpene effects and should receive special attention.

\section{Antioxidative Effects}

$\nabla$

ROS are well recognised as playing a dual role as both deleterious and beneficial species. ROS are normally generated by tightly regulated enzymes to maintain moderate concentrations, provid- ing beneficial physiological effects, for example in cellular responses to noxia, or in the regulation of immune responses. Overproduction results in oxidative stress that can be an important mediator of damage to cell structures [78]. Initially increased levels of ROS disrupt cell membrane integrity by oxidation of unsaturated membrane lipids. Lipid peroxidation is commonly related to cardiovascular diseases [79], autoimmune diseases or chronic inflammation [80]. Furthermore, free radicals cause DNA damage which may result in tumour initiation and promotion [81]. Thus regulation of the ROS level may be an important preventive measure and may also support the anticancer therapies, by avoiding oxidative stress.

The organism uses two antioxidative mechanisms to regulate the level of free radicals, first an enzymatic and second a non-enzymatic system $[82,83]$. The enzymatic system concerns enzymes such as superoxide dismutase (SOD) or catalase (CAT) that are oxidised and reduced within a cascade to eliminate the free radicals. The non-enzymatic system deals with antioxidants. One of the body's own antioxidants is glutathione (GSH). It exists as a monomeric tripeptide (GSH); when oxidised a GSSG dimer is generated. In order to use the reducing power of glutathione to catalyze disulfide reductions in the presence of NADPH and glutathione reductase, enzymes such as glutathione-S-transferase and glutathione peroxidase are necessary [84].

Triterpenes, particularly lupeol, but also betulin and ursolic acid are known for their antioxidative potential [85-90]. They do not act as a classical antioxidant; however, triterpenes activate the enzymatic system by increasing the activity of SOD as well as CAT and glutathione S-transferase and glutathione peroxidase [90-92].

In detail, lupeol especially displays convincing effects particularly on chronic inflammatory diseases such as chronic arthritis, but also as a chemoprotective agent. When arthritic rats were treated orally with lupeol ( $50 \mathrm{mg} / \mathrm{kg}$ body weight daily for 8 days), a significant decrease of the inflammatory symptoms was observed, while the activity of the antioxidative enzymes SOD and CAT were elevated [93]. Another positive effect of lupeol is documented in the case of hyperoxaluria in rats [94]. The excess of oxalate causes a high oxidative stress on the renal tissue. Similar to lupeol, betulin ( $35 \mathrm{mg} / \mathrm{kg}$ body weight daily for 21 days) normalises the glutathione status, increases the SOD and CAT activity [90] and decreases the peroxidation of erythrocyte membrane lipids as well as normalises the activity of membrane bound ATPases [92]. A third indication that has been investigated is hypercholesterolemia. Lupeol ( $50 \mathrm{mg} / \mathrm{kg}$ body weight daily) normalises the lipid profile and activates the body's own antioxidative system followed by a decrease of oxidative stress in rats. This results in a protection of renal tissue. In this case the antioxidative effect of lupeol is called cardioprotective or renalprotective $[87,95,96]$. In the majority of in vivo studies lupeol and also betulin were administered orally daily without any adverse effects at a dosage of $35-50 \mathrm{mg} / \mathrm{kg}$ body weight, which is a high dose. Considering an average human body weight of $60 \mathrm{~kg}$, the application of $3 \mathrm{~g}$ of the drug per day would be necessary.

The diseases mentioned are not directly related to the development of cancer, but they illustrate the antioxidative activity of lupeol or betulin. This seems to be not only a central part of their biological activity but also the basic mechanism of their chemopreventive effects which may avoid cancer development.

Substances that cause cell damage, particularly DNA damage or induce chronic inflammations are potential carcinogens. Agents that shield the organism from these attacks are called chemopre- 
ventive. Recently lupeol was termed as a chemopreventive agent, reviewed by Chaturvedi and colleagues [7]. This includes hepatoprotective effects protecting liver cells from cadmium, 7,12-dimethylbenz(a)anthracene (DMBA) or hepatotoxic aflatoxins [97-100] or cardioprotective activity shielding cardiac tissue from cyclophosphamide induced cardiotoxicity [88] by oral administration of lupeol. Furthermore, a chemoprotective effect of topically applied lupeol was observed when skin was treated with benzoylperoxides [89,101] or DMBA [102]. All these potential carcinogenic agents cause oxidative stress, deplete glutathione and decrease the activity of antioxidant enzymes. Lupeol regenerates the glutathione pool along with an elevation in the activities of the antioxidising enzymes and anti-oxidants.

Further cytoprotective effects are also known for betulin and triterpene acids. In vitro pretreatment with 2 and $22 \mu \mathrm{M}$ ursolic acid protects human lymphocytes against UVB-induced lipid peroxidation and DNA-damage concentration-dependently [86]. Various in vitro studies revealed hepatoprotective effects of betulin, betulinic, ursolic and oleanolic acid against cadmium or ethanol-induced toxicity in HepG2 cells $(2-11 \mu \mathrm{M})[103,104]$. It should be mentioned that these effects occur using subtoxic triterpene concentrations depending on the cell type. Recently published data showed chemopreventive activity of oleanolic and ursolic acid also in vivo. Rats treated orally with 1,2-dimethylhydrazine developed colon associated carcinogenic dysplasia caused by agent-induced oxidative stress. Simultaneous oral administration of $25 \mathrm{mg} / \mathrm{kg}$ body weight oleanolic or ursolic acid decreases the appearance of cell damage [105].

Further experiments focussed on hepatoprotective effects have identified a possible key target for the antioxidative effect of triterpenes. Oleanolic acid treatment dramatically increased expression of the transcription factor nuclear factor E2-related factor 2 (Nrf2) [106]. Regulatory regions of the genes for cytoprotective enzymes such as glutathione S-transferase or SOD contain the antioxidant response element (ARE), which is activated upon binding of Nrf2. Nrf2 has been shown to be essential in the upregulation of these genes in response to oxidative stress [107]. The mechanism of increasing Nrf2 expression by oleanolic acid has not been clarified so far. One hypothesis might be the generation of ROS that triggers the antioxidative cascade including Nrf2 expression. For oleanolic acid treatment at concentrations of $25 \mu \mathrm{M}$, accumulation of ROS in an astrocytoma cell line resulting in apoptosis has been reported [20], but it was interpreted only in the context of apoptosis induction. Also betulinic acid (20$100 \mu \mathrm{M})$ showed ROS generation at concentrations resulting in apoptosis $[18,24]$. Therefore the question arises, whether generation of ROS could be induced by triterpenes or especially by triterpene acids used in a subtoxic concentration, and if this could lead to an activation of the antioxidative system.

Taken together, lupeol and betulin, as well as triterpene acids, such as oleanolic acid and ursolic acid, display an antioxidative activity. The underlying mechanism is the modulation of the body's own enzymatic antioxidative system including enzymes such as SOD and CAT, as well as glutathione S-transferase, perhaps triggered by the activation of Nrf2 and leading to a generally elevated antioxidant status of the organism. The antioxidative effect of triterpenes seems to be a central part of their biological activity and may also be useful as a preventive strategy in the case of cancer.

\section{Redifferentiation}

\section{$\nabla$}

Differentiation and proliferation of a cell are mutually exclusive. Differentiation takes place in the G0 state of a cell. In order to proliferate, reentering the cell cycle is necessary. Thus, achieving differentiation of a still proliferating cancer cell is one possible approach of cancer treatment. In this respect, compounds that influence and enhance differentiation processes in cells are promising candidates for cancer therapy. In case of triterpenes, very interesting data reveal the promotion of differentiation of healthy cells such as keratinocytes and also of the redifferentiation of tumour cells.

With regard to differentiation of healthy cells, it was shown that betulinic acid induces differentiation in normal keratinocytes in vitro at concentrations of $9-18 \mu \mathrm{M}$, including an upregulation of filaggrin and involucrin [11]. Likewise, oleanolic acid, but not ursolic acid, increases the expression of these two differentiation markers in vivo in mouse skin disrupted by tape stripping. Oleanolic acid not only upregulated structural proteins localised in the spinous/granular layers in the epidermis, but also the cornified envelope formation as the final product of terminal differentiation was increased and the barrier function of the epidermis was regenerated, as measured by a decreased transepidermal water loss [108]. Similar results were obtained with a highly purified triterpene dry extract from birch bark consisting of betulin ( $80 \%)$, betulinic acid, oleanolic acid, and lupeol (1-4\%). Normal human keratinocytes and human skin explants were treated with $10 \mu \mathrm{g} / \mathrm{mL}$ of the extract. Besides the upregulation of early and late differentiation markers such as loricrin, filaggrin, involucrin, transglutaminase, and keratin 10, as well as increased Notch2 expression, also a typical degradation of DNA strictly limited to the distal stratum granulosum cells was observed [109].

One possible signalling cascade activated by triterpenes is the peroxisome proliferator activated receptor- $\alpha$ (PPAR- $\alpha$ ) pathway, which is involved in the regulation of lipid metabolism in the epidermis [110]. Oleanolic acid and ursolic acid topically applied on disrupted mouse skin improved the recovery of permeability barrier functions and stimulated epidermal differentiation via PPAR$\alpha$ expression $[108,111]$. Another hypothesis is the selective upregulation of the transient receptor potential channel 6 (TRPC6) by triterpenes in primary keratinocytes [109]. TRPC6 is a calcium channel mediating differentiation by regulating the $\mathrm{Ca}^{2+}$ influx into the keratinocytes [112].

Besides the upregulation of differentiation markers, or the activation of corresponding signalling pathways, morphological changes are also an important part of the differentiation of many cell types and, therefore, a useful additional marker to recognise differentiation. Thus, the morphological change of primary keratinocytes into a typical hexagonal corneocyte shape under triterpene acid treatment encourages the suggestion of their differentiation-inducing efficacy $[11,108]$. Also mammary epithelial cells of rats as well as tumour cells, such as tetracarcinoma stem cells [113], showed morphological changes when treated with oleanolic acid or ursolic acid [114]. Not only triterpene acids induce such morphological changes, but also treatment with lupeol results in modifications of the cell shape, e.g., of the mouse melanoma cell line B16 2F2, and an inhibition of the ability of the cells to migrate, thus reducing their malignant potential [115]. The morphological changes mediated by alterations of the cytoskeleton are accompanied by the degradation and reconstruction of microfilaments consisting of actin, whereas the actin content of the cells remains constant $[20,115,116]$. Up to now it is not clear whether 
these changes are directly induced by triterpenoids or are a result of the activated differentiation process. But it should be mentioned that morphological changes could also be observed in the apoptosis process induced by triterpenes [20]. Therefore the interpretation of this phenomenon must be carefully evaluated.

Moreover, differentiation is also indicated by regaining or developing special cell type specific properties. For example, myeloid leukaemia cells (HL-60) amplify 1-alpha,25-dihydroxyvitamin D3 induced monocytic marker expression such as CD11b or CD14 when treated additionally with betulinic acid [117]. Oleanolic acid decreases the proliferation rate of M1 mouse carcinoma cells and human leukaemia cells (HL-60) while phagocytotic activity is increased. And lupeol as well as betulin and betulinic acid induce melanogenesis in B16 2F2 mouse melanoma cells [118].

The ability to induce differentiation or redifferentiation, instead of acting as a cytotoxic substance, is always a question of the available triterpene concentration and depends also on cell type and cell status [109]. Until now some mechanistic investigations have been carried out only in keratinocytes, revealing two possible targets: PPAR- $\alpha$ and TRPC6. For other cell types, the observations were only of the differentiation process or the outcome, for example, morphological changes, developing special abilities such as phagocytotic activity or expressing differentiation markers such as CD11b or CD14 in the case of myeloid leukaemia cells. The differentiation data are still fragmentary, but here the potential of triterpenes seems to be worth investigating in detail.

\section{Anticancer Activity in vivo}

$\nabla$

The relevance of in vitro results can only be judged against subsequent in vivo studies. Because of this, the strong interest on pentacyclic triterpenes as anticancer agents did not start until betulinic acid was found to be effective in vivo against melanoma by Pisha et al. in 1995 [119].

Bioavailability is the precondition of in vivo effects. Only a few pharmacokinetic studies have been published. BA was found in various tissues $24 \mathrm{~h}$ after i.p. administration ( $500 \mathrm{mg} / \mathrm{kg}$; mouse) and reached its highest concentration in perirenal fat. Peak serum concentration of $4.0 \mu \mathrm{g} / \mathrm{mL}$ was observed at $0.23 \mathrm{~h}$ after application [120]. BE reaches a saturation concentration of $138 \mathrm{ng} /$ $\mathrm{mL}$ within $4 \mathrm{~h}$ after i.p. administration to rats [121]. These relatively low serum levels can be explained by the low solubility in water (BA, OA: $0.02 \mu \mathrm{g} / \mathrm{mL}$ and $\mathrm{BE}<0.1 \mu \mathrm{g} / \mathrm{mL}$ ) [62,122]. It is known that $\mathrm{OA}$ is able to bind to plasmin and albumin [17,21], so binding phenomena could support the bioavailability. Thus the prediction of in vivo effects and the concentrations necessary for them may be unreliable if based on in vitro results.

For instance, cytotoxicity was shown for lupeol combating testosterone-induced prostate enlargement in mice, by inducing apoptosis in the hypodiploid regions, and in tumours with human prostate origin in a xenograft model $[28,123]$. Recent findings showed that lupeol ( $40 \mathrm{mg} / \mathrm{kg}$ body weight thrice a week) also inhibits the growth of highly aggressive human metastatic melanoma cells $(451 \mathrm{Lu})$ in an athymic nude mouse xenograft model. Immunohistochemical analysis of tumour tissue revealed that animals receiving lupeol exhibit decreased Ki67 and PCNA-positive cells, suggesting an antiproliferative effect of lupeol. This correlated with a decreased number of cyclin D1, cyclin D2 and Cdk2 positive cells and an elevated level of p21 protein compared to the control mice. The latter result indicates that lupeol causes growth arrest in melanoma tumours by interfering with the cyclin/cdk2/p21 complex activity [124].

Modern cancer treatment also includes modulation of the immune system. As noted above, in vitro a broad spectrum of immune modulations by triterpenes is observed. Indeed, this could be confirmed in some in vivo studies, e.g., in a study using melanoma (B16.F10) bearing mice (C57BL/6). I.p. injected ursolic or oleanolic acid ( $50 \mu \mathrm{mol} / \mathrm{kg}$ body weight, for 5 days) was found to produce enhanced natural killer cell activity and increased the cytokine IL-2 that promotes the lytic activity of NK cells. In addition, antibody-dependent cell mediated cytotoxicity (ADCC) as well as antibody-dependent complement-mediated cytotoxicity (ACC) were enhanced. According to the expected anticancer effect, the elevated levels of GM-CSF and IL-6 in tumour-bearing control animals were also reduced by the treatment with ursolic acid [125]. Another study showed lupeol efficacy in a TPA induced mouse skin tumourigenesis model (CD1) by its anti-inflammatory activity. Prior topical application of 1-2 mg/animal lupeol resulted in the inhibition of the TPA induced activation of PI3K and NF- $k$ B and in an inhibition of COX-2 and iNOS protein expression. The mice showed significant reduced tumour incidence, lower tumour burden and a delay in the latency period for tumour appearance [76].

While the antiangiogenic effect of ursolic acid in vitro was still being discussed, Lee et al. (2001) proposed this kind of anticancer effect based on in vivo studies. Reduced oxygen consumption after treatment as well as a significant decreased tumour interstitial fluid and blood pressure were obtained after i.p. application of $100 \mathrm{mg} / \mathrm{kg}$ body weight ursolic acid. This was accompanied by an inhibited tumour growth of a murine fibrosarcoma (FSaII) [126]. The inhibitory action of ursolic acid on urokinase as observed in vitro was assumed to be important with respect not only to the antiangiogenic effect but also to the suppression of tumour-invasion and metastasis. An in vivo study on B16 mouse melanoma treated C57BL/6 mice showed the complete inhibition of lung colonisation after $50 \mathrm{mg} / \mathrm{kg}$ ursolic acid administered i.p. daily, immediately after tumour injection during 16 consecutive days. The authors proposed that besides the in vitro observed urokinase inhibition activity of ursolic acid, an inhibition of cathepsin B, which represents another possible drug target for the suppression of tumour invasion and metastasis, may also play a crucial role [41]. Comparable results with respect to tumour metastasis were found for betulinic acid $(10 \mathrm{mg} / \mathrm{kg}$ body weight per day) when used in a similar experimental setup [127]. As already mentioned above, betulinic acid targets VEGF expression in a prostate cancer mouse model and induces the selective proteasome-mediated degradation of transcription factor specificity protein Sp1, Sp3 and Sp4 [47].

Another approach for the usage of triterpenes in cancer-therapy is their combination with established chemotherapeutics. In vivo studies using an orthotopic metastatic nude mouse model of oral tongue squamous cell carcinoma showed that lupeol $(2 \mathrm{mg} / \mathrm{kg}$ body weight) dramatically decreased the tumour volume and suppressed local metastasis without side effects. It was 3-fold more effective than cisplatin, a commonly used chemotherapeutic agent with severe side effects. Surprisingly, lupeol in combination with low-dose cisplatin was 13-fold more potent than lupeol alone and up to 40-fold more than cisplatin alone, certainly without side effects in the animal model used [128]. In another study betulinic acid augmented the inhibitory effect of vincristine, the major chemotherapeutic agent used for the treatment of melanoma [127]. Combination with triterpenes allowed reduction of the 
concentration of the chemotherapeutic agent, without loosing the effectiveness of treatment, while side effects were decreased. As mentioned previously, up to now there has been only very limited experience in the treatment of human cancer patients with the listed triterpenoids. It should be mentioned, that in animal studies dosages of between 10 and $100 \mathrm{mg} / \mathrm{kg}$ body weight are applied which is between 0.6 and $6 \mathrm{~g}$ per patient per application ( $60 \mathrm{~kg}$ body weight assumed). This is an unusually high amount for a drug, and the feasibility and the relevance of this dose is questionable. Nevertheless, betulinic acid is currently undergoing a phase II clinical trial for dysplastic melanocytic naevus (web site: ClinicalTrials.gov). Beside this, recent data show the successful topical treatment of precancerous lesions, namely actinic keratoses, with a triterpene dry extract (TE) of the outer bark of birch as mentioned above [37]. Immunohistochemical investigations of biopsies before and after a three month treatment with TE showed a downstaging of the actinic keratosis and a reorganised epidermal structure.

It has been possible to confirm in vivo all the general effects of the triterpenes discussed that were predicted based on in vitro data (inducing apoptosis, anti-inflammatory, antiangiogenic and antioxidative effects), except for the redifferentiation effect. In this case, the observation of the downstaging of actinic keratosis lesions after a three month treatment with triterpenes in a clinical trial has been the only observation available until now, but there is no experimental work. Thus it is too soon to claim a re-differentiation effect for the triterpenes in cancer treatment; however it is a promising field of triterpene research.

Administration of drugs also raises the question of their toxicity in vivo. Pentacyclic triterpenes of the lupane, oleanane and ursane group are considered as relatively nontoxic drugs. A recently published subchronic toxicity study showed that intraperitoneal and subcutaneous administration of a triterpene mixture $(80 \%$ betulin, betulinic acid, lupeol, oleanolic acid, erythrodiol 1-4\%) produces no toxic effects [121]. This is in line with previously published data for single triterpenes. For example, i.p. administered oleanolic acid has a LD50 of $1500 \mathrm{mg} / \mathrm{mL}$ in mice [129] and a single s.c. dose of $1000 \mathrm{mg} / \mathrm{mL}$ caused no toxic effects in rats [130]. Also i.p. administration of $500 \mathrm{mg} / \mathrm{kg}$ body weight betulinic acid in suspension caused no toxicity [131]. As summarised previously, administration of betulin or lupeol at concentrations of $35-50 \mathrm{mg} / \mathrm{kg}$ body weight also produces no toxic effects.

\section{Conclusion}

$\nabla$

Cancer is a disease with multiple etiological factors and multiple oncogenes are involved in its pathogenesis. Therefore, beside a combination of different treatment strategies, multifunctional agents with multiple targets also offer a more rational approach than single ones to both its prevention and therapy.

The literature survey reveals that lupeol, betulin, betulinic acid, oleanolic and ursolic acid are multitarget agents ( $\boldsymbol{O}$ Fig. 2 ). They fit to the concept of modern cancer therapy, by treating cancer from different sides, including the tumour environment and the immune system.

But parallel testing of these compounds revealed differences in their efficacy in several assays. Therefore, the combination of different triterpenes may be a way to improve their potential as multitarget drugs. Plants like white birch, rosemary, or mistletoe offer different natural compositions of triterpenes, and their triterpene extracts may be used as starting material for further pharmaceutical development.
Another possible application is combining triterpenes with already commonly used chemotherapeutic agents. This may allow lowering the chemotherapeutic dose without loss of efficacy but hopefully brings with it less adverse effects and may even give synergistic effects.

The pharmacological potential of triterpenes for cancer treatment seems to be high, although up to now no clinical trial has been published using triterpenes in cancer therapy. This may be explained by their almost complete insolubility in water [5,122]. But this galenic problem can be solved by derivatisation, complexation [132,133], or liposomal formulation [134]. Another problem might be that triterpenes often provide only moderate effects in vitro, perhaps due to their poor solubility [122] and the use of solvents such as dimethylsulfoxide (DMSO) that are not inert. In our experience, using $1 \%$ DMSO in cell culture medium, a maximum concentration between 20 and $40 \mu \mathrm{g} / \mathrm{ml}$ triterpenes is possible without crystallisation but it has to be carefully checked in each case. Nonetheless they exhibit convincing effects when applied in vivo, as seen in the case of the birch bark TE extract. Further, the high dose that is used in animal tests might be an obstacle to transferring it to a therapeutic dose used in human treatment. Up to now, only two clinical trials have been carried out with these substances, one treating actinic keratosis and another dysplastic melanocytic naevus. In each case topical ointments were used. Internal application, such as s.c. or i.v., has not yet been tested in human cancer treatment.

Looking into future, there remains some tasks to do in order to tap the full potential of these triterpenes. A lot of effects are not fully understood like the antioxidative efficacy or the differentiation effects. Another point is that the strength of each single compound is not defined detailed enough, to find their optimal domain or to compose them. The differences between the experimental settings, the used concentrations, time courses or the various cell lines, with different metabolic background and varying cell culture parameters, makes it difficult to compare and combine results to get an idea of the underlying mechanisms. Therefore, parallel-testing of triterpenes in a standardised setting would be preferable. Due to their insolubility in water the bioavailability is not given in an optimal way, nevertheless, in vivo effects are observed. This may be improved by optimising the galenic form or the application route.

Their chemopreventive activity makes triterpenes interesting in another field. As secondary plant metabolites they are present in food. For example, due to the common use of olives and herbs such as rosemary of the Lamiaceae family, the Mediterranean diet is high in triterpenes. It is not proven yet, whether they are responsible for the beneficial effects of this nutrition on health.

In conclusion pentacyclic triterpenes are a rich natural pool of promising anticancer drugs as well as chemopreventive agents. Further, they are available in high amounts also in industrial waste products like birch bark or the pulpy residue from apples. This and their promising pharmacological effects warrants further pharmaceutical development and clinical investigations to conclude the puzzle of their biological activities.

\section{Acknowledgements}

$\nabla$

The author thanks Stefan F. Martin, Sebastian Jäger, Irmgard Merfort and David J. Heaf for expert assistance and critical reading in preparation of the manuscript. 


\section{References}

1 Trosko JE. The role of stem cells and gap junctions as targets for cancer chemoprevention and chemotherapy. Biomed Pharmacother 2005; 59 (Suppl. 2): 326-331

2 Brenner DE, Gescher AJ. Cancer chemoprevention: lessons learned and future directions. Br J Cancer 2005; 93: 735-739

$3 \mathrm{Xu}$ R, Fazio GC, Matsuda SP. On the origins of triterpenoid skeletal diversity. Phytochemistry 2004; 65: 261-291

4 Ekman $R$. The submarin monomers and triterpenoids from the outer bark of Betula verrucosa EHRH. Holzforschung 1983; 37: 205-211

5 Laszczyk M, Jäger S, Simon-Haarhaus B, Scheffler A, Schempp CM. Physical, chemical and pharmacological characterization of a new oleogelforming triterpene extract from the outer bark of birch (betulae cortex). Planta Med 2006; 72: 1389-1395

6 Jäger S, Trojan H, Kopp T, Laszczyk MN, Scheffler A. Pentacyclic triterpene distribution in various plants - rich sources for a new group of multi-potent plant extracts. Molecules 2009; 14: 2016-2031

7 Chaturvedi PK, Bhui K, Shukla Y. Lupeol: connotations for chemoprevention. Cancer Lett 2008; 263: 1-13

8 Ovesna Z, Vachalkova A, Horvathova K, Tothova D. Pentacyclic triterpenoic acids: new chemoprotective compounds. Minireview. Neoplasma 2004; 51: 327-333

9 Fulda S. Betulinic acid: a natural product with anticancer activity. Mol Nutr Food Res 2009; 53: 140-146

10 Fulda S, Jeremias I, Steiner HH, Pietsch T, Debatin KM. Betulinic acid: a new cytotoxic agent against malignant brain-tumor cells. Int J Cancer 1999; 82: 435-441

11 Galgon T, Wohlrab W, Dräger B. Betulinic acid induces apoptosis in skin cancer cells and differentiation in normal human keratinocytes. Exp Dermatol 2005; 14: 736-743

12 Kessler JH, Mullauer FB, de Roo GM, Medema JP. Broad in vitro efficacy of plant-derived betulinic acid against cell lines derived from the most prevalent human cancer types. Cancer Lett 2007; 251: 132-145

13 Selzer E, Pimentel E, Wacheck V, Schlegel W, Pehamberger H, Jansen B, Kodym $R$. Effects of betulinic acid alone and in combination with irradiation in human melanoma cells. J Invest Dermatol 2000; 114: 935-940

14 Zuco V, Supino R, Righetti SC, Cleris L, Marchesi E, Gambacorti-Passerini $C$, Formelli $F$. Selective cytotoxicity of betulinic acid on tumor cell lines, but not on normal cells. Cancer Lett 2002; 175: 17-25

15 Wachsberger PR, Burd R, Wahl ML, Leeper DB. Betulinic acid sensitization of low pH adapted human melanoma cells to hyperthermia. Int J Hyperthermia 2002; 18: 153-164

16 Noda Y, Kaiya T, Kohda K, Kawazoe Y. Enhanced cytotoxicity of some triterpenes toward leukemia L1210 cells cultured in low pH media: possibility of a new mode of cell killing. Chem Pharm Bull (Tokyo) 1997; 45: $1665-1670$

17 Fulda S, Scaffidi C, Susin SA, Krammer PH, Kroemer G, Peter ME, Debatin $K M$. Activation of mitochondria and release of mitochondrial apoptogenic factors by betulinic acid. J Biol Chem 1998; 273: 33942-33948

18 Tan Y, Yu R, Pezzuto JM. Betulinic acid-induced programmed cell death in human melanoma cells involves mitogen-activated protein kinase activation. Clin Cancer Res 2003; 9: 2866-2875

19 Liu WK, Ho JC, Cheung FW, Liu BP, Ye WC, Che CT. Apoptotic activity of betulinic acid derivatives on murine melanoma B16 cell line. Eur J Pharmacol 2004; 498: 71-78

20 Martin R, Carvalho J, Ibeas E, Hernandez M, Ruiz-Gutierrez V, Nieto ML. Acidic triterpenes compromise growth and survival of astrocytoma cell lines by regulating reactive oxygen species accumulation. Cancer Res 2007; 67: 3741-3751

21 Mullauer FB, Kessler JH, Medema JP. Betulinic acid induces cytochrome c release and apoptosis in a Bax/Bak-independent, permeability transition pore dependent fashion. Apoptosis 2009; 14: 191-202

22 Fulda S, Friesen C, Los M, Scaffidi C, Mier W, Benedict M, Nunez G, Krammer PH, Peter ME, Debatin KM. Betulinic acid triggers CD95 (APO-1/Fas)- and p53-independent apoptosis via activation of caspases in neuroectodermal tumors. Cancer Res 1997; 57: 4956-4964

23 Selzer E, Thallinger C, Hoeller C, Oberkleiner P, Wacheck V, Pehamberger $H$, Jansen $B$. Betulinic acid-induced Mcl-1 expression in human melanoma-mode of action and functional significance. Mol Med 2002; 8: 877-884

24 Wick W, Grimmel C, Wagenknecht B, Dichgans J, Weller M. Betulinic acid-induced apoptosis in glioma cells: a sequential requirement for new protein synthesis, formation of reactive oxygen species, and caspase processing. J Pharmacol Exp Ther 1999; 289: 1306-1312
25 Rzeski W, Stepulak A, Szymanski M, Sifringer M, Kaczor J, Wejksza K, Zdzisinska B, Kandefer-Szerszen M. Betulinic acid decreases expression of bcl-2 and cyclin D1, inhibits proliferation, migration and induces apoptosis in cancer cells. Naunyn Schmiedebergs Arch Pharmacol 2006; 374: 11-20

26 Kasperczyk H, La Ferla-Bruhl K, Westhoff MA, Behrend L, Zwacka RM, Debatin KM, Fulda S. Betulinic acid as new activator of NF-kappaB: molecular mechanisms and implications for cancer therapy. Oncogene 2005; 24: 6945-6956

27 Rabi T, Shukla S, Gupta S. Betulinic acid suppresses constitutive and TNFalpha-induced NF-kappaB activation and induces apoptosis in human prostate carcinoma PC-3 cells. Mol Carcinogen 2008; 47: 964-973

28 Saleem M, Kweon MH, Yun JM, Adhami VM, Khan N, Syed DN, Mukhtar H. A novel dietary triterpene Lupeol induces fas-mediated apoptotic death of androgen-sensitive prostate cancer cells and inhibits tumor growth in a xenograft model. Cancer Res 2005; 65: 11 203-11213

29 Murtaza I, Saleem M, Adhami VM, Hafeez BB, Mukhtar H. Suppression of cFLIP by lupeol, a dietary triterpene, is sufficient to overcome resistance to TRAIL-mediated apoptosis in chemoresistant human pancreatic cancer cells. Cancer Res 2009; 69: 1156-1165

30 Saleem M, Kaur S, Kweon MH, Adhami VM, Afaq F, Mukhtar H. Lupeol, a fruit and vegetable based triterpene, induces apoptotic death of human pancreatic adenocarcinoma cells via inhibition of Ras signaling pathway. Carcinogenesis 2005; 26: 1956-1964

31 Manu KA, Kuttan G. Ursolic acid induces apoptosis by activating p 53 and caspase-3 gene expressions and suppressing NF-kappaB mediated activation of bcl-2 in B16F-10 melanoma cells. Int Immunopharmacol 2008; 8: 974-981

32 Zhang P, Li H, Chen D, Ni J, Kang Y, Wang S. Oleanolic acid induces apoptosis in human leukemia cells through caspase activation and poly (ADP-ribose) polymerase cleavage. Acta Biochim Biophys Sin (Shanghai) 2007; 39: 803-809

33 Kim DS, Pezzuto JM, Pisha E. Synthesis of betulinic acid derivatives with activity against human melanoma. Bioorg Med Chem Lett 1998; 8: 1707-1712

34 Hata K, Hori K, Ogasawara H, Takahashi S. Anti-leukemia activities of Lup-28-al-20(29)-en-3-one, a lupane triterpene. Toxicol Lett 2003; 143: $1-7$

35 Pyo JS, Roh SH, Kim DK, Lee JG, Lee YY, Hong SS, Kwon SW, Park JH. Anticancer effect of betulin on a human lung cancer cell line: a pharmacoproteomic approach using 2D SDS PAGE coupled with nano-HPLC tandem mass spectrometry. Planta Med 2009; 75: 127-131

36 Juan ME, Wenzel U, Daniel H, Planas JM. Erythrodiol, a natural triterpenoid from olives, has antiproliferative and apoptotic activity in HT-29 human adenocarcinoma cells. Mol Nutr Food Res 2008; 52: 595-599

37 Huyke C, Reuter J, Rodig M, Kersten A, Laszczyk M, Scheffler A, Nashan D, Schempp $C$. Treatment of actinic keratoses with a novel betulin-based oleogel. A prospective, randomized, comparative pilot study. J Dtsch Dermatol Ges 2009; 7: 128-133

38 Sohn KH, Lee HY, Chung HY, Young HS, Yi SY, Kim KW. Anti-angiogenic activity of triterpene acids. Cancer Lett 1995; 94: 213-218

39 Kiran MS, Viji RI, Sameer Kumar VB, Sudhakaran PR. Modulation of angiogenic factors by ursolic acid. Biochem Biophys Res Commun 2008; 371: $556-560$

40 Cardenas C, Quesada AR, Medina MA. Effects of ursolic acid on different steps of the angiogenic process. Biochem Biophys Res Commun 2004; 320: 402-408

41 Jedinak A, Muckova M, Kost'alova D, Maliar T, Masterova I. Antiprotease and antimetastatic activity of ursolic acid isolated from Salvia officinalis. Z Naturforsch [C] 2006; 61: 777-782

42 Melzig MF, Bormann $\mathrm{H}$. Betulinic acid inhibits aminopeptidase $\mathrm{N}$ activity. Planta Med 1998; 64: 655-657

43 Bauvois B, Dauzonne D. Aminopeptidase-N/CD13 (EC 3.4.11.2) inhibitors: chemistry, biological evaluations, and therapeutic prospects. Med Res Rev 2006; 26: 88-130

44 Bhagwat SV, Lahdenranta J, Giordano R, Arap W, Pasqualini R, Shapiro $L H$. CD13/APN is activated by angiogenic signals and is essential for capillary tube formation. Blood 2001; 97: 652-659

45 Kwon HJ, Shim JS, Kim JH, Cho HY, Yum YN, Kim SH, Yu J. Betulinic acid inhibits growth factor-induced in vitro angiogenesis via the modulation of mitochondrial function in endothelial cells. Jpn J Cancer Res 2002; 93: 417-425

46 Lee MS, Moon EJ, Lee SW, Kim MS, Kim KW, Kim YJ. Angiogenic activity of pyruvic acid in in vivo and in vitro angiogenesis models. Cancer Res 2001; 61: 3290-3293 
47 Chintharlapalli S, Papineni S, Ramaiah SK, Safe S. Betulinic acid inhibits prostate cancer growth through inhibition of specificity protein transcription factors. Cancer Res 2007; 67: 2816-2823

48 You YJ, Nam NH, Kim Y, Bae KH, Ahn BZ. Antiangiogenic activity of lupeol from Bombax ceiba. Phytother Res 2003; 17: 341-344

49 Mantovani A, Allavena P, Sica A, Balkwill F. Cancer-related inflammation. Nature 2008; 454: 436-444

50 Ahmad SF, Khan B, Bani S, Suri KA, Satti NK, Qazi GN. Amelioration of adjuvant-induced arthritis by ursolic acid through altered Th1/Th2 cytokine production. Pharmacol Res 2006; 53: 233-240

51 Altinier G, Sosa S, Aquino RP, Mencherini T, Della Loggia R, Tubaro A. Characterization of topical antiinflammatory compounds in Rosmarinus officinalis L. J Agric Food Chem 2007; 55: 1718-1723

52 Banno N, Akihisa T, Tokuda H, Yasukawa K, Higashihara H, Ukiya M, Watanabe K, Kimura Y, Hasegawa J, Nishino H. Triterpene acids from the leaves of Perilla frutescens and their anti-inflammatory and antitumor-promoting effects. Biosci Biotechnol Biochem 2004; 68: 85-90

53 de la Puerta R, Martinez-Dominguez E, Ruiz-Gutierrez V. Effect of minor components of virgin olive oil on topical antiinflammatory assays. Z Naturforsch [C] 2000; 55: 814-819

54 Fernandez MA, de las Heras B, Garcia MD, Saenz MT, Villar A. New insights into the mechanism of action of the anti-inflammatory triterpene lupeol. J Pharm Pharmacol 2001; 53: 1533-1539

55 Miceli N, Taviano MF, Giuffrida D, Trovato A, Tzakou O, Galati EM. Antiinflammatory activity of extract and fractions from Nepeta sibthorpii Bentham. J Ethnopharmacol 2005; 97: 261-266

56 Recio MC, Giner RM, Manez S, Gueho J, Julien HR, Hostettmann K, Rios JL. Investigations on the steroidal anti-inflammatory activity of triterpenoids from Diospyros leucomelas. Planta Med 1995; 61: 9-12

57 Alakurtti S, Makela T, Koskimies S, Yli-Kauhaluoma J. Pharmacological properties of the ubiquitous natural product betulin. Eur J Pharm Sci 2006; 29: 1-13

58 Cichewicz RH, Kouzi SAL. Chemistry, biological activity, and chemotherapeutic potential of betulinic acid for the prevention and treatment of cancer and HIV infection. Med Res Rev 2004; 24: 90-114

59 Eiznhamer $D A, X u Z Q$. Betulinic acid: a promising anticancer candidate. IDrugs 2004; 7: 359-373

60 Bani S, Kaul A, Khan B, Ahmad SF, Suri KA, Gupta BD, Satti NK, Qazi GN. Suppression of T-lymphocyte activity by lupeol isolated from Crataeva religiosa. Phytother Res 2006; 20: 279-287

61 Kang SY, Yoon SY, Roh DH, Jeon MJ, Seo HS, Uh DK, Kwon YB, Kim HW, Han HJ, Lee HJ, Lee JH. The anti-arthritic effect of ursolic acid on zymosan-induced acute inflammation and adjuvant-induced chronic arthritis models. J Pharm Pharmacol 2008; 60: 1347-1354

62 Laszczyk MN. Triterpentrockenextrakt aus Birkenkork (Betula alba cortex) [dissertation]. Freiburg: Albert-Ludwigs-University; 2007

63 Yun Y, Han S, Park E, Yim D, Lee S, Lee CK, Cho K, Kim K. Immunomodulatory activity of betulinic acid by producing pro-inflammatory cytokines and activation of macrophages. Arch Pharm Res 2003; 26: 1087-1095

64 Ikeda Y, Murakami A, Fujimura Y, Tachibana H, Yamada K, Masuda D, Hirano K, Yamashita S, Ohigashi H. Aggregated ursolic acid, a natural triterpenoid, induces IL-1beta release from murine peritoneal macrophages: role of CD36. J Immunol 2007; 178: 4854-4864

65 Marquez-Martin A, De La Puerta R, Fernandez-Arche A, Ruiz-Gutierrez V, Yaqoob $P$. Modulation of cytokine secretion by pentacyclic triterpenes from olive pomace oil in human mononuclear cells. Cytokine 2006; 36: 211-217

66 Vasconcelos MA, Royo VA, Ferreira DS, Crotti AE, Andrade e Silva ML, Carvalho JC, Bastos JK, Cunha WR. In vivo analgesic and anti-inflammatory activities of ursolic acid and oleanoic acid from Miconia albicans (Melastomataceae). Z Naturforsch [C] 2006; 61: 477-482

67 Van Waes C. Nuclear factor-kappaB in development, prevention, and therapy of cancer. Clin Cancer Res 2007; 13: 1076-1082

68 Takada Y, Aggarwal BB. Betulinic acid suppresses carcinogen-induced NF-kappa B activation through inhibition of I kappa B alpha kinase and p 65 phosphorylation: abrogation of cyclooxygenase- 2 and matrix metalloprotease-9. J Immunol 2003; 171: 3278-3286

69 Shishodia S, Majumdar S, Banerjee S, Aggarwal BB. Ursolic acid inhibits nuclear factor-kappaB activation induced by carcinogenic agents through suppression of IkappaBalpha kinase and p 65 phosphorylation: correlation with down-regulation of cyclooxygenase 2, matrix metalloproteinase 9, and cyclin D1. Cancer Res 2003; 63: 4375-4383

70 You HJ, Choi CY, Kim JY, Park SJ, Hahm KS, Jeong HG. Ursolic acid enhances nitric oxide and tumor necrosis factor-alpha production via nuclear
factor-kappaB activation in the resting macrophages. FEBS Lett 2001; 509: 156-160

71 Choi CY, You HJ, Jeong HGL. Nitric oxide and tumor necrosis factor-alpha production by oleanolic acid via nuclear factor-kappaB activation in macrophages. Biochem Biophys Res Commun 2001; 288: 49-55

72 Suh N, Honda T, Finlay HJ, Barchowsky A, Williams C, Benoit NE, Xie QW, Nathan C, Gribble GW, Sporn MB. Novel triterpenoids suppress inducible nitric oxide synthase (iNOS) and inducible cyclooxygenase (COX-2) in mouse macrophages. Cancer Res 1998; 58: 717-723

73 Bernard P, Scior T, Didier B, Hibert M, Berthon JYL. Ethnopharmacology and bioinformatic combination for leads discovery: application to phospholipase A(2) inhibitors. Phytochemistry 2001; 58: 865-874

74 Dharmappa KK, Kumar RV, Nataraju A, Mohamed R, Shivaprasad HV, Vishwanath BS. Anti-inflammatory activity of oleanolic acid by inhibition of secretory phospholipase A2. Planta Med 2009; 75: 211-215

75 Reyes CP, Nunez MJ, Jimenez IA, Busserolles J, Alcaraz MJ, Bazzocchi IL. Activity of lupane triterpenoids from Maytenus species as inhibitors of nitric oxide and prostaglandin E2. Bioorg Med Chem 2006; 14: 1573-1579

76 Saleem M, Afaq F, Adhami VM, Mukhtar H. Lupeol modulates NF-kappaB and PI3K/Akt pathways and inhibits skin cancer in CD-1 mice. Oncogene 2004; 23: 5203-5214

77 Telliez A, Furman C, Pommery N, Henichart JP. Mechanisms leading to COX-2 expression and COX-2 induced tumorigenesis: topical therapeutic strategies targeting COX-2 expression and activity. Anticancer Agents Med Chem 2006; 6: 187-208

78 Valko M, Leibfritz D, Moncol J, Cronin MT, Mazur M, Telser J. Free radicals and antioxidants in normal physiological functions and human disease. Int J Biochem Cell Biol 2007; 39: 44-84

79 Castelao JE, Gago-Dominguez M. Risk factors for cardiovascular disease in women: relationship to lipid peroxidation and oxidative stress. Med Hypotheses 2008; 71: 39-44

80 Leitinger $N$. The role of phospholipid oxidation products in inflammatory and autoimmune diseases: evidence from animal models and in humans. Subcell Biochem 2008; 49: 325-350

81 Valko M, Rhodes CJ, Moncol J, Izakovic M, Mazur M. Free radicals, metals and antioxidants in oxidative stress-induced cancer. Chem Biol Interact 2006: 160: 1-40

82 Kalpakcioglu B, Senel $K$. The interrelation of glutathione reductase, catalase, glutathione peroxidase, superoxide dismutase, and glucose-6phosphate in the pathogenesis of rheumatoid arthritis. Clin Rheumatol 2008; 27 : $141-145$

83 Afonso V, Champy $R$, Mitrovic D, Collin P, Lomri A. Reactive oxygen species and superoxide dismutases: role in joint diseases. Joint Bone Spine 2007; 74: 324-329

84 Fernandes AP, Holmgren A. Glutaredoxins: glutathione-dependent redox enzymes with functions far beyond a simple thioredoxin backup system. Antioxid Redox Signal 2004; 6: 63-74

85 Prasad S, Kalra N, Singh M, Shukla Y. Protective effects of lupeol and mango extract against androgen induced oxidative stress in Swiss albino mice. Asian J Androl 2008; 10: 313-318

86 Ramachandran S, Prasad NR. Effect of ursolic acid, a triterpenoid antioxidant, on ultraviolet-B radiation-induced cytotoxicity, lipid peroxidation and DNA damage in human lymphocytes. Chem Biol Interact 2008; 176: 99-107

87 Sudhahar V, Ashok Kumar S, Varalakshmi P, Sujatha V. Protective effect of lupeol and lupeol linoleate in hypercholesterolemia associated renal damage. Mol Cell Biochem 2008; 317: 11-20

88 Sudharsan PT, Mythili Y, Selvakumar E, Varalakshmi P. Cardioprotective effect of pentacyclic triterpene, lupeol and its ester on cyclophosphamide-induced oxidative stress. Hum Exp Toxicol 2005; 24: 313-318

89 Sultana S, Saleem M, Sharma S, Khan N. Lupeol, a triterpene, prevents free radical mediated macromolecular damage and alleviates benzoyl peroxide induced biochemical alterations in murine skin. Indian J Exp Biol 2003; 41: 827-831

90 Malini MM, Lenin M, Varalakshmi P. Protective effect of triterpenes on calcium oxalate crystal-induced peroxidative changes in experimental urolithiasis. Pharmacol Res 2000; 41: 413-418

91 Geetha T, Varalakshmi P. Anticomplement activity of triterpenes from Crataeva nurvala stem bark in adjuvant arthritis in rats. Gen Pharmacol 1999; 32: 495-497

92 Vidya L, Malini MM, Varalakshmi P. Effect of pentacyclic triterpenes on oxalate-induced changes in rat erythrocytes. Pharmacol Res 2000; 42: 313-316 
93 Geetha T, Varalakshmi P, Latha RM. Effect of triterpenes from Crataeva nurvala stem bark on lipid peroxidation in adjuvant induced arthritis in rats. Pharmacol Res 1998; 37: 191-195

94 Vidya L, Varalakshmi P. Control of urinary risk factors of stones by betulin and lupeol in experimental hyperoxaluria. Fitoterapia 2000; 71: 535-543

95 Sudhahar V, Ashokkumar S, Varalakshmi P. Effect of lupeol and lupeol linoleate on lipemic - hepatocellular aberrations in rats fed a high cholesterol diet. Mol Nutr Food Res 2006; 50: 1212-1219

96 Sudhahar V, Kumar SA, Sudharsan PT, Varalakshmi P. Protective effect of lupeol and its ester on cardiac abnormalities in experimental hypercholesterolemia. Vasc Pharmacol 2007; 46: 412-418

97 Prasad S, Kalra N, Shukla Y. Hepatoprotective effects of lupeol and mango pulp extract of carcinogen induced alteration in Swiss albino mice. Mol Nutr Food Res 2007; 51: 352-359

98 Preetha SP, Kanniappan M, Selvakumar E, Nagaraj M, Varalakshmi P. Lupeol ameliorates aflatoxin B1-induced peroxidative hepatic damage in rats. Comp Biochem Physiol C Toxicol Pharmacol 2006; 143 : 333-339

99 Nagaraj M, Sunitha S, Varalakshmi P. Effect of lupeol, a pentacyclic triterpene, on the lipid peroxidation and antioxidant status in rat kidney after chronic cadmium exposure. J Appl Toxicol 2000; 20: 413-417

100 Sunitha S, Nagaraj M, Varalakshmi P. Hepatoprotective effect of lupeol and lupeol linoleate on tissue antioxidant defence system in cadmium-induced hepatotoxicity in rats. Fitoterapia 2001; 72: 516-523

101 Saleem M, Alam A, Arifin S, Shah MS, Ahmed B, Sultana S. Lupeol, a triterpene, inhibits early responses of tumor promotion induced by benzoyl peroxide in murine skin. Pharmacol Res 2001; 43: 127-134

102 Nigam N, Prasad S, Shukla Y. Preventive effects of lupeol on DMBA induced DNA alkylation damage in mouse skin. Food Chem Toxicol 2007; 45: 2331-2335

103 Miura N, Matsumoto Y, Miyairi S, Nishiyama S, Naganuma A. Protective effects of triterpene compounds against the cytotoxicity of cadmium in HepG2 cells. Mol Pharmacol 1999; 56: 1324-1328

104 Szuster-Ciesielska A, Kandefer-Szerszen M. Protective effects of betulin and betulinic acid against ethanol-induced cytotoxicity in HepG2 cells. Pharmacol Rep 2005; 57: 588-595

105 Furtado RA, Rodrigues EP, Araujo FR, Oliveira WL, Furtado MA, Castro $M B$, Cunha WR, Tavares DC. Ursolic acid and oleanolic acid suppress preneoplastic lesions induced by 1,2-dimethylhydrazine in rat colon. Toxicol Pathol 2008; 36: 576-580

106 Liu J, Wu Q Lu YF, Pi J. New insights into generalized hepatoprotective effects of oleanolic acid: key roles of metallothionein and Nrf2 induction. Biochem Pharmacol 2008; 76: 922-928

107 Eggler AL, Gay KA, Mesecar AD. Molecular mechanisms of natural products in chemoprevention: induction of cytoprotective enzymes by Nrf2. Mol Nutr Food Res 2008; 52 (Suppl. 1): S84-S94

108 Lee KH, Nam GW, Kim SH, Lee SH. Phytocomponents of triterpenoids, oleanolic acid and ursolic acid, regulated differently the progressing of epidermal keratinocytes via PPAR-a pathway. Exp Dermatol 2006; 15: 66-73

109 Woelfle ULM, Kraus M, Leuner K, Kersten A, Simon-Haarhaus B, Scheffler A, Martin SF, Müller WE, Nashan D, Schempp CM. Triterpenes promote keratinocyte differentiation in vitro, ex vivo and in vivo. A role for the transient receptor potential canonical (subtype) 6. JID, Epub ahead of print August 13, 2009; DOI: 10.1038/jid.2009.248

110 Schmuth M, Jiang YJ, Dubrac S, Elias PM, Feingold KR. Thematic review series: skin lipids. Peroxisome proliferator-activated receptors and liver X receptors in epidermal biology. J Lipid Res 2008; 49: 499-509

111 Lim SW, Hong SP, Jeong SW, Kim B, Bak H, Ryoo HC, Lee SH, Ahn SK. Simultaneous effect of ursolic acid and oleanolic acid on epidermal permeability barrier function and epidermal keratinocyte differentiation via peroxisome proliferator-activated receptor-alpha. J Dermatol 2007; 34: 625-634

112 Muller M, Essin K, Hill K, Beschmann H, Rubant S, Schempp CM, Gollasch M, Boehncke WH, Harteneck C, Muller WE, Leuner K. Specific TRPC6 channel activation, a novel approach to stimulate keratinocyte differentiation. J Biol Chem 2008; 283: 33942-33954

113 Lee HY, Chung HY, Kim KH, Lee JJ, Kim KW. Induction of differentiation in the cultured F9 teratocarcinoma stem cells by triterpene acids. J Cancer Res Clin Oncol 1994; 120: 513-518
114 Paik KJ, Jeon SS, Chung HY, Lee KH, Kim KW, Chung JK, Kim ND. Induction of differentiation of the cultured rat mammary epithelial cells by triterpene acids. Arch Pharm Res 1998; 21: 398-405

115 Hata K, Hori K, Murata J, Takahashi S. Remodeling of actin cytoskeleton in lupeol-induced B16 2F2 cell differentiation. J Biochem 2005; 138: 467-472

116 Ogiwara K, Hata K. Melanoma cell differentiation induced by lupeol separates into two stages: morphological and functional changes. Nat Med (Tokyo) 2009; 63: 323-326

117 Poon KH, Zhang J, Wang C, Tse AK, Wan CK, Fong WF. Betulinic acid enhances 1alpha,25-dihydroxyvitamin D3-induced differentiation in human HL-60 promyelocytic leukemia cells. Anticancer Drugs 2004; 15: 619-624

118 Hata K, Hori K, Takahashi S. Differentiation- and apoptosis-inducing activities by pentacyclic triterpenes on a mouse melanoma cell line. J Nat Prod 2002; 65: 645-648

119 Pisha E, Chai H, Lee IS, Chagwedera TE, Farnsworth NR, Cordell GA Beecher CW, Fong HH, Kinghorn AD, Brown DM, Wani MC, Wall ME, Hieken TJ, Das Gupta TK, Pezzuto JM. Discovery of betulinic acid as a selective inhibitor of human melanoma that functions by induction of apoptosis. Nat Med 1995; 1: 1046-1051

120 Udeani GO, Zhao GM, Geun Shin Y, Cooke BP, Graham J, Beecher CW, Kinghorn AD, Pezzuto JM. Pharmacokinetics and tissue distribution of betulinic acid in CD-1 mice. Biopharm Drug Dispos 1999; 20: 379-383

121 Jäger S, Laszczyk MN, Scheffler A. A preliminary pharmacokinetic study of betulin, the main pentacyclic triterpene from extract of outer bark of birch (Betulae alba cortex). Molecules 2008; 13: 3224-3235

122 Jäger S, Winkler K, Pfüller U, Scheffler A. Solubility studies of oleanolic acid and betulinic acid in aqueous solutions and plant extracts of Viscum album L. Planta Med 2007; 73: 157-162

123 Prasad S, Kalra N, Shukla Y. Induction of apoptosis by lupeol and mango extract in mouse prostate and LNCaP cells. Nutr Cancer 2008; 60: 120-130

124 Saleem M, Maddodi N, Abu Zaid M, Khan N, bin Hafeez B, Asim M, Suh Y, Yun JM, Setaluri V, Mukhtar $H$. Lupeol inhibits growth of highly aggressive human metastatic melanoma cells in vitro and in vivo by inducing apoptosis. Clin Cancer Res 2008; 14: 2119-2127

125 Raphael TJ, Kuttan G. Effect of naturally occurring triterpenoids ursolic acid and glycyrrhizic acid on the cell-mediated immune responses of metastatic tumor-bearing animals. Immunopharmacol Immunotoxicol 2008; 30: 243-255

126 Lee I, Lee J, Lee YH, Leonard J. Ursolic acid-induced changes in tumor growth, $\mathrm{O} 2$ consumption, and tumor interstitial fluid pressure. Anticancer Res 2001; 21: 2827-2833

127 Sawada N, Kataoka K, Kondo K, Arimochi H, Fujino H, Takahashi Y, Miyoshi T, Kuwahara T, Monden Y, Ohnishi Y. Betulinic acid augments the inhibitory effects of vincristine on growth and lung metastasis of B16F10 melanoma cells in mice. Br J Cancer 2004; 90: 1672-1678

128 Lee TK, Poon RT, Wo JY, Ma S, Guan XY, Myers JN, Altevogt P, Yuen AP. Lupeol suppresses cisplatin-induced nuclear factor-kappaB activation in head and neck squamous cell carcinoma and inhibits local invasion and nodal metastasis in an orthotopic nude mouse model. Cancer Res 2007; 67: 8800-8809

129 Liu J. Pharmacology of oleanolic acid and ursolic acid. J Ethnopharmacol 1995; 49: 57-68

130 Singh GB, Singh S, Bani S, Gupta BD, Banerjee SK. Anti-inflammatory activity of oleanolic acid in rats and mice. J Pharm Pharmacol 1992; 44: $456-458$

131 Shin YG, Cho KH, Chung SM, Graham J, Das Gupta TK, Pezzuto JM. Determination of betulinic acid in mouse blood, tumor and tissue homogenates by liquid chromatography-electrospray mass spectrometry. J Chromatogr B Biomed Sci Appl 1999; 732: 331-336

132 Guo M, Zhang S, Song F, Wang D, Liu Z, Liu S. Studies on the non-covalent complexes between oleanolic acid and cyclodextrins using electrospray ionization tandem mass spectrometry. J Mass Spectrom 2003; 38: 723-731

133 Strüh C, Jäger S, Schempp CM, Scheffler A, Martin SF. Solubilized triterpenes from mistletoe show anti-tumor effects on skin-derived cell lines. Planta Med 2008; 74: 1130

134 Kang HS, Park JE, Lee YJ, Chang IS, Chung YI, Tae G. Preparation of liposomes containing oleanolic acid via micelle-to-vesicle transition. J Nanosci Nanotechnol 2007; 7: 3944-3948 